\title{
Milkvetch root improves immune function in patients with acute exacerbation of COPD
}

\author{
Donglin Jiang, ${ }^{\mathrm{a}, \mathrm{b}}, \mathrm{Xu}$ Wang $^{\mathrm{b}}$, Qiang Su ${ }^{\mathrm{b}}$, Shengyang Jiang ${ }^{\mathrm{a}}$, Fenglai Yuan ${ }^{\mathrm{a}}$, Caidi Zhang ${ }^{\mathrm{b}}$, \\ Fang Gong ${ }^{\mathrm{a}}$, Qiaojing Dong ${ }^{\mathrm{b}}$, Jianping Shi ${ }^{\mathrm{b}}$ and Baohua Chen ${ }^{\mathrm{b}, *}$ \\ ${ }^{a}$ Wuxi Institute of Integrated Traditional Chinese and Western Medicine, the Third Affiliated Hospital \\ to Nantong University, Wuxi, Jiangsu Province, China \\ ${ }^{b}$ Department of Respiratory Diseases, Wuxi Hospital of Integrated Traditional Chinese and Western \\ Medicine, the Third Affiliated Hospital to Nantong University, Wuxi, Jiangsu Province, China
}

\begin{abstract}
Milkvetch root as a medicine has been used for more over 2000 years in China, can strengthen immune function, protect liver, promote urination, resist aging and stress, reduce blood pressure and extensively resist bacterium. This study explored the effects of milkvetch root on the immune function of patients with a definitive diagnosis of acute exacerbation of chronic obstructive pulmonary disease (COPD). The patients were randomly assigned to either the experimental or control group. All patients received conventional clinical therapy; those in the experimental group were also administered milkvetch root. The serum levels of cytokines including tumor necrosis factor alpha (TNF- $\alpha$ ), interleukin-8 (IL-8), IL-1 $\beta$, and IL-32 and immunocytes including $\mathrm{T}$ helper $(\mathrm{Th})$, cytotoxic $\mathrm{T}(\mathrm{Tc})$, natural killer $(\mathrm{NK})$, regulatory $\mathrm{T}$ (Treg) and B cells were measured 1 day before treatment and 7 and 14 days post-treatment. After bronchodilator inhalation, pulmonary function was evaluated at these same time points. The serum TNF- $\alpha$, IL- 8 , IL- $1 \beta$, and IL-32 levels were significantly lower in the experimental group than in the control group 14 days post-treatment. The Th/Tc ratio and NK cell ratio was significantly higher but the Treg cell ratio was significantly lower in the experimental group than in the control group. The forced expiratory volume in 1 second (FEV1) and FEV1/forced vital capacity (FVC) were significantly higher in the experimental group than in the control group 14 days post-treatment. These results indicate that milkvetch root can improve the immune function of patients with acute exacerbation of COPD.
\end{abstract}

Keywords: Chronic obstructive pulmonary disease, milkvetch root, immune function

\section{Introduction}

Chronic obstructive pulmonary disease (COPD) is induced by chronic bronchitis and emphysema. It is characterized by reversible airflow obstruction with clinical progression and represents a serious public health concern worldwide [1,2]. Chronic inflammation involving the lung parenchyma, airways, and pulmonary vessels is the basis of disease progression in patients with COPD. This is particularly evident in acute exacerbation of COPD, which is characterized by substantial activation of inflammatory cells and release of inflammatory factors and media. Improvement in the quality of life

\footnotetext{
* Address for correspondence: Baohua Chen, Department of Respiratory Diseases, the Third Affiliated Hospital to Nantong University; No. 585 Xing-Yuan North Road, Beitang District, Wuxi, Jiangsu Province; P.R. China 214041 Tel.: +8615301516183; Fax: +860510 82602557; E-mail: wxsy66566@163.com.
} 
of patients with COPD is dependent upon taking effective therapeutic measures, controlling the inflammatory reaction, and improving pulmonary function [3-5]. Many clinicians practicing modern medicine believe that milkvetch root can improve the body's immune function [6-8]. Based on traditional Chinese medicine theory, this study combined milkvetch root and conventional treatment methods in patients with acute exacerbation of COPD and observed the effects of milkvetch root on stabilization of the patients' immune status.

\section{Patients and methods}

\subsection{Patients}

In total, 82 patients with acute exacerbation of COPD diagnosed at the Third Affiliated Hospital of Nantong University in China from April 2012 to October 2013 were enrolled in this study. Each patient was randomly assigned to either the control group $(n=41 ; 21$ men and 20 women; age, 51-90 years) or the experimental group ( $\mathrm{n}=41 ; 22$ men and 19 women; age, 46-93 years) based on their sequence of hospital admission. The inclusion criteria were as follows: the diagnosis of acute exacerbation of COPD was achieved in accordance with the Guideline for Diagnosis and Treatment of COPD (2007 Revised Edition) formulated by the Chinese Society of Respiratory Diseases of the Chinese Medical Association [9]; local and systemic hormones had not been used within 3 months prior to enrollment; and pulmonary function could be measured at the time of admission. The exclusion criteria were as follows: respiratory system diseases other than COPD; left ventricular systolic or diastolic dysfunction; hemopathy; malignant tumors; systemic autoimmune disease; other infectious disease; severe endocrine, liver, or kidney disease; or recent surgery. This study was performed in accordance with medical ethical standards and was approved by our institution's Hospital Ethics Committee. All patients provided written informed consent to participate.

\subsection{Therapeutic regimen}

Antispasmodic, expectorant, antiasthmatic, and anti-infection treatments were performed in accordance with Guideline for Diagnosis and Treatment of COPD (2007 Revised Edition). The experimental group also received $15 \mathrm{mg}$ of astragalus granules (JiangyinTianjiang Pharmaceutical Co., Ltd.) with water twice a day for 14 consecutive days.

\subsection{Evaluation of pulmonary function}

All patients in both the experimental and control groups inhaled $5 \mathrm{mg}$ of the bronchodilator terbutaline on the day of admission and in the morning at 7 and 14 days after admission in the conscious state. Fifteen minutes later, pulmonary function parameters were measured using a spirometer (MasterScreen, Jaeger, Germany), and the forced vital capacity (FVC), forced expiratory volume in 1 second (FEV1), and FEV1/FVC ratio were recorded. FEV1 and FEV1/FVC are adopted as diagnostic indicators for the determination of the airflow limitation in patients with COPD; FEV1/FVC can be used to determine a mild airflow limitation while the percentage of FEV1 in a predicted value is used as a good index for the determination of midrange or severe airflow limitation. They are the routine testing items in clinic for COPD pulmonary function examination. 


\subsection{Measurement of cytokines and immunocytes}

After the patients had fasted, $5 \mathrm{ml}$ of venous blood was collected on the day of admission and in the morning at 7 and 14 days after admission in both the experimental and control groups. The blood samples were placed in an unheated drying tube (serum was isolated within 2 hours and stored at $80^{\circ} \mathrm{C}$, and inflammatory cytokines were measured) and in a tube containing the anticoagulant ethylenediaminetetraacetic acid (immunocytes were evaluated the same day). The inflammatory cytokines measured were tumor necrosis factor alpha (TNF- $\alpha$ ), interleukin-8 (IL-8), IL-1 $\beta$, and IL-32. The ELISA kit used in this study was purchased from eBioscience (San Diego, CA, USA), and the SpectraMax 340 microplate reader was purchased from Molecular Devices, Inc. (Sunnyvale, CA, USA). The immunocytes measured were $\mathrm{T}$ helper (Th) cells $\left(\mathrm{CD}^{+} / \mathrm{CD}^{+}\right.$cells), cytotoxic $\mathrm{T}(\mathrm{Tc})$ cells $\left(\mathrm{CD}^{+} / \mathrm{CD}^{+}\right.$cells), natural killer $(\mathrm{NK})$ cells $\left(\mathrm{CD} 3^{-} / \mathrm{CD} 16 / 56^{+}\right.$cells), regulatory $\mathrm{T}$ (Treg) cells $\left(\mathrm{CD}^{+} / \mathrm{CD} 25^{+} / \mathrm{Foxp}^{3+}\right.$ cells $)$, and $\mathrm{B}$ cells $\left(\mathrm{CD}^{-} / \mathrm{CD} 19^{+}\right.$cells $)$. Flow cytometry was performed (FACSCalibur; BD Biosciences, San Jose, CA, USA). All procedures were conducted in precise accordance with the manufacturer's instructions.

\subsection{Statistical methods}

All data were analyzed using SPSS 10.0 software (SPSS Inc., Chicago, IL, USA). Intragroup comparisons at different time points in both groups were performed using the two-sample t-test. Intergroup comparison at the same time point was performed using the two-independent-samples t-test. Qualitative data in both groups were compared using the chi-squared test in four-fold table. The testing standard for all hypothesis tests was set at $\alpha=0.05$. A value of $P<0.05$ was considered to be statistically significant.

\section{Results}

\subsection{Quantitative analysis of patients}

Of all 82 patients with COPD, 6 from the control group and 3 from the experimental group were excluded because of data loss, replacement therapy, or early discharge. In total, 73 patients $(35$ in the control group and 38 in the experimental group) were included in the final analysis.

\subsection{Comparison of baseline data between the two groups}

No significant differences in age $(73.18 \pm 10.79$ years vs. $74.17 \pm 10.20$ years; $\mathrm{t}=0.388, \mathrm{P}=0.699)$ or sex (male/female: $20 / 18$ vs. $16 / 19 ; \chi 2=0.349, \mathrm{P}=0.555$ ) were detected between the experimental and control groups (all $\mathrm{P}>0.05)$. Additionally, no significant differences in FEV1 $(52.34 \% \pm 7.13 \%$ vs. $51.57 \% \pm 7.53 \% ; \mathrm{t}=0.443, \mathrm{P}=0.659)$ or FEV1/FVC $(56.75 \% \pm 9.44 \%$ vs. $57.49 \% \pm 9.08 \% ; \mathrm{t}=$ $0.341, \mathrm{P}=0.734$ ) were detected between the experimental and control groups (all $\mathrm{P}>0.05$ ). Finally, no significant differences in the immunological parameters were observed before treatment between the experimental and control groups (all $\mathrm{P}>0.05$ ) (Table 1). 
Table 1

Comparison of immunological parameters before treatment in the experimental and control groups

\begin{tabular}{llllll}
\hline Group & Case & IL-8(ng/L) & IL-1 $\beta(\mathrm{ng} / \mathrm{L})$ & TNF- $\alpha(\mathrm{ng} / \mathrm{L})$ & IL-32(ng/L) \\
\hline Control & 35 & $59.25 \pm 9.31$ & $12.22 \pm 3.72$ & $67.39 \pm 9.58$ & $32.34 \pm 4.69$ \\
Experimental & 38 & $58.18 \pm 8.72$ & $12.68 \pm 3.39$ & $68.49 \pm 10.04$ & $31.61 \pm 5.19$ \\
$\mathrm{t}$ & & 0.510 & 0.550 & 0.481 & 0.630 \\
$\mathrm{P}$ & & 0.612 & 0.584 & 0.632 & 0.531 \\
\hline \multirow{2}{*}{ Group } & \multirow{2}{*}{ Case } & Treg cell ratio & Th/Tc ratio & NK cell ratio & B cell ratio \\
& & $(\%)$ & $(\%)$ & $(\%)$ & $(\%)$ \\
\hline Control & 35 & $8.42 \pm 1.79$ & $1.15 \pm 0.33$ & $12.08 \pm 4.83$ & $10.72 \pm 2.41$ \\
Experimental & 38 & $8.55 \pm 1.68$ & $1.11 \pm 0.32$ & $11.47 \pm 4.10$ & $10.61 \pm 2.21$ \\
$\mathrm{t}$ & & 0.311 & 0.542 & 0.581 & 0.219 \\
$\mathrm{P}$ & & 0.756 & 0.590 & 0.563 & 0.828 \\
\hline Note: IL: interleukin, TNF: tumor necrosis factor, Treg: regulatory T cell, Th: T helper cell, Tc: cytotoxic T cell, NK: natural killer cell
\end{tabular}

\section{A.}

$\square$ Control group

Experimental group

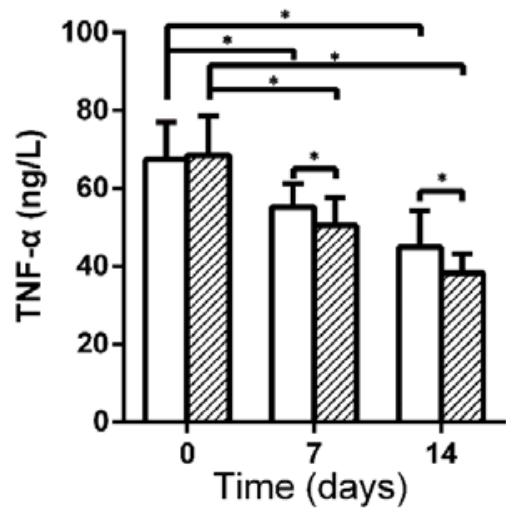

C.
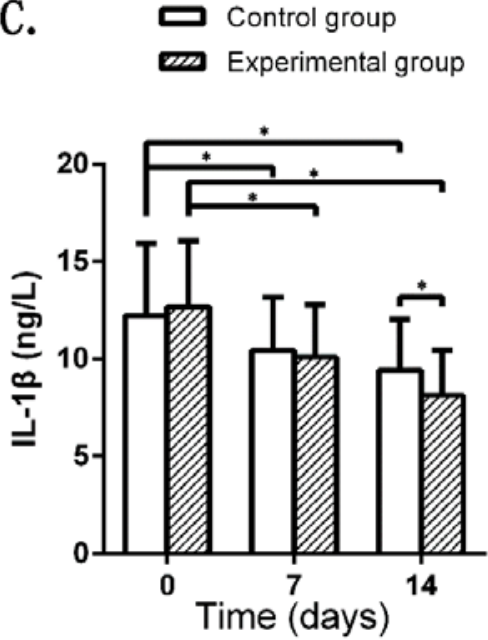

B.
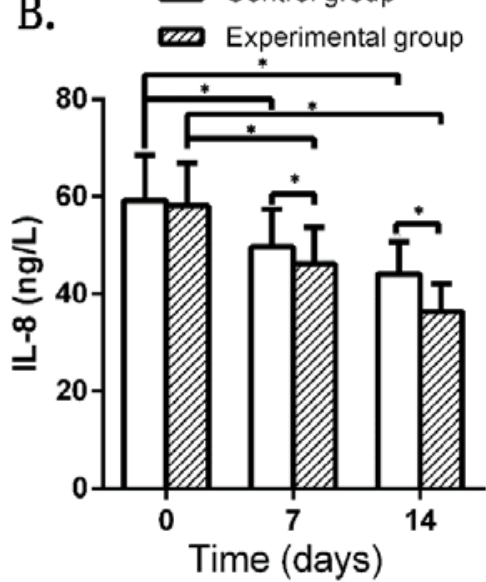

D. $\square$ Control group

Experimental group

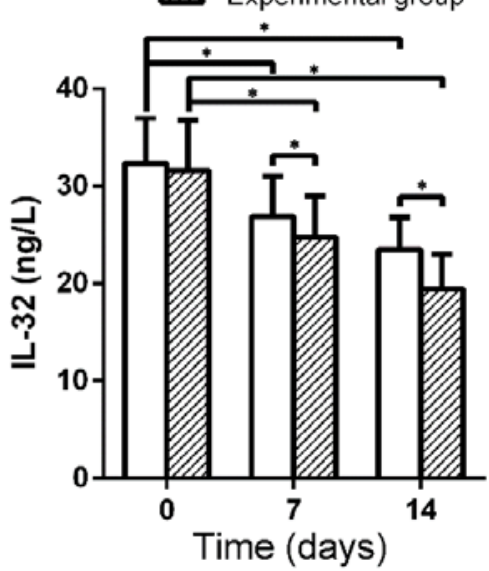

Fig. 1. TNF- $\alpha$, IL-8, IL-1 $\beta$, and IL-32 levels were significantly lower in the experimental group than in the control group after 7 and 14 days post-treatment. The blood samples were detected by homologousELISAkits.A. TNF- $\alpha$; B. IL-8; C. IL-1 $\beta$; D. IL-32.TNF: tumor necrosis factor, IL: interleukin, $* P<0.05$. 


\subsection{Comparison of inflammatory cytokines between the experimental and control groups}

The TNF- $\alpha$, IL-8, IL-1 $\beta$, and IL-32 levels were significantly lower 7 and 14 days after treatment than the levels before treatment in both the experimental and control groups (all $\mathrm{P}<0.05$ ). The TNF- $\alpha$, IL-8, IL-1 $\beta$, and IL-32 levels were significantly lower in the experimental group than in the control group 7 and 14 days post-treatment (all $\mathrm{P}<0.05$ ) (Figure 1).

\subsection{Comparison of NK, Treg, and B cell and Th/Tc ratio changes between the experimental and control groups}

The NK and $\mathrm{B}$ cell and $\mathrm{Th} / \mathrm{Tc}$ ratios were significantly higher but the Treg cell ratio was significantly lower 14 days after treatment in both the experimental and control groups (all $\mathrm{P}<0.05$ ). $\mathrm{The} \mathrm{Th} / \mathrm{Tc}$ ratio was significantly higher in the experimental group than in the control group 7 days after treatment $(\mathrm{P}<0.05)$. The NK cell ratio was significantly higher but the Treg cell ratio was significantly lower in the experimental group than in the control group at 14 days $(\mathrm{P}<0.05)$. No significant difference in the $\mathrm{B}$ cell ratio was detected between the experimental and control groups at 14 days $(\mathrm{P}>0.05)$ (Figure 2$)$.
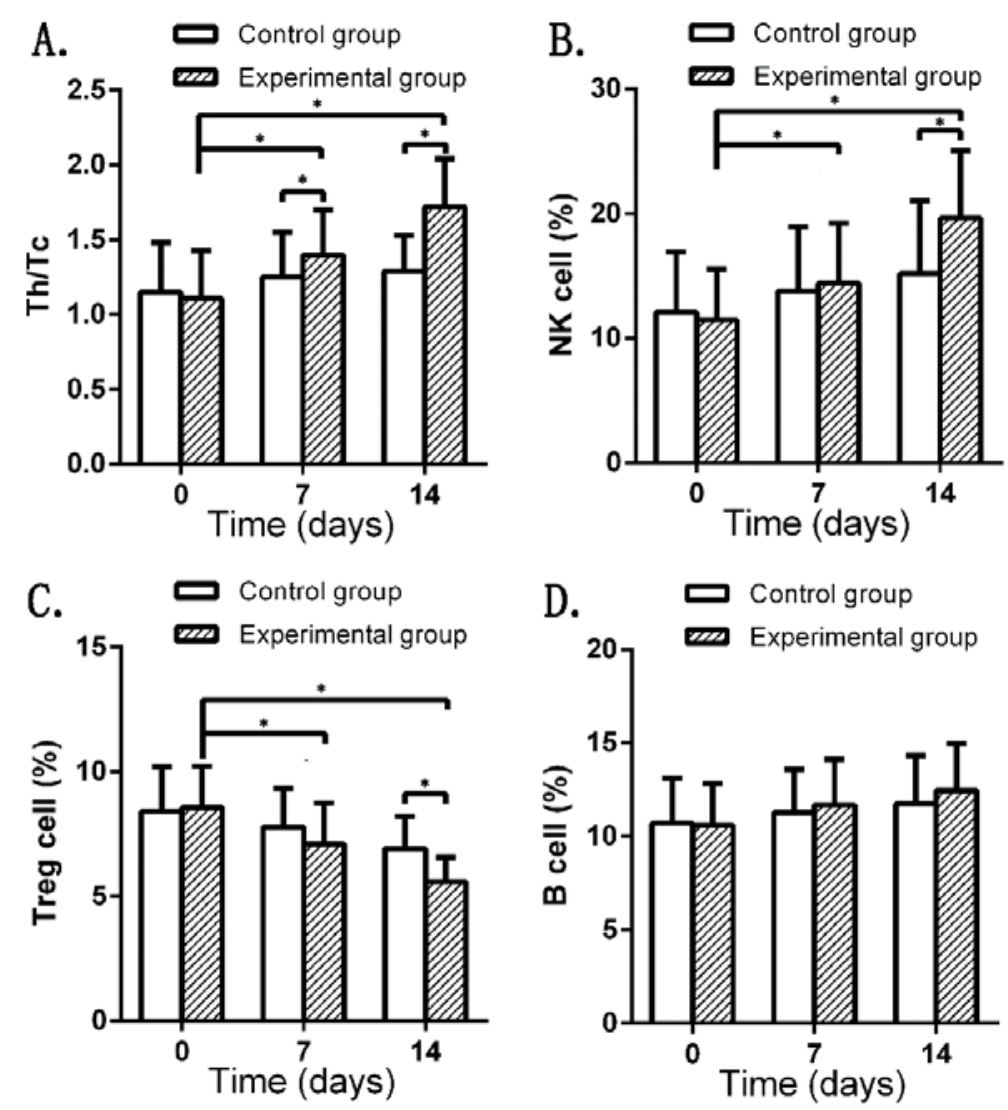

Fig. 2. Comparison of NK, Treg, and B cells and $\mathrm{Th} / \mathrm{Tc}$ ratio between the experimental and control groups according to treatment time. $\mathrm{Th} / \mathrm{Tc}$ ratio and NK cell ratio were significantly higher but the Treg cell ratio was significantly lower in the experimental group than in the control group after 14 days post-treatment. A. Th/Tc ratio; B. NK cell ratio; C. Treg cell ratio; D. B cell.NK: natural killer cell, Treg: regulatory T cell, Th: T helper cell, Tc: cytotoxic T cell; $* P<0.05$. 

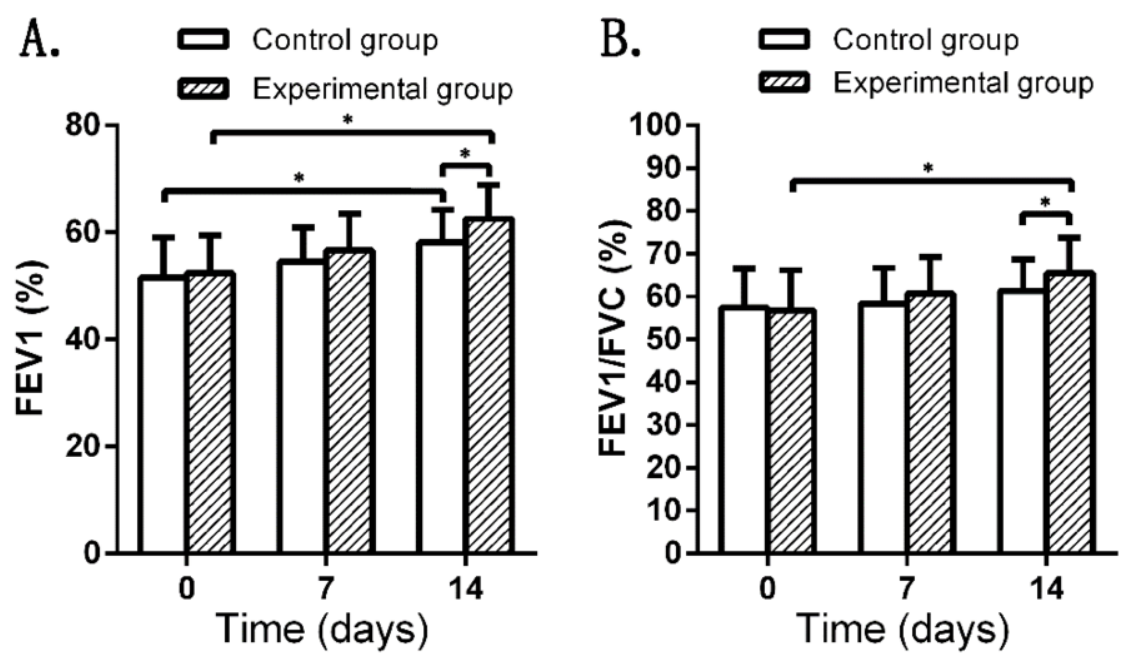

Fig. 3. FEV1 and FEV1/FVC were significantly higher in the experimental group than in the control group after 14 days posttreatment. A. FEV1; B. FEV1/FVC.FEV1: forced expiratory volume in 1 second, FVC: forced vital capacity, ${ }^{*} \mathrm{P}<0.05$.

\subsection{Alterations in FEV1 and FEV1/FVC between the experimental and control groups}

FEV1 and FEV1/FVC were significantly higher 7 and 14 days after treatment than before treatment in both the experimental and control groups $(\mathrm{P}<0.05)$. FEV1 and FEV1/FVC were significantly higher in the experimental group than in the control group at 14 days post-treatment $(\mathrm{P}<0.05)$ (Figure $3)$.

\subsection{Adverse reactions}

In the experimental group, two patients developed mild diarrhea and one developed abdominal distension; both conditions resolved after symptomatic treatment. No adverse reactions were observed in the control group.

\section{Discussion}

Patients with COPD have immune dysfunction. Viral or bacterial infections are met with poor resistance and immune imbalance [10] characterized by decreases in the $\mathrm{Th} / \mathrm{Tc}$ ratio, NK cells, and $\mathrm{B}$ cells $[11,12]$; increases in neutrophil and Treg cell stress (For Treg cells, it could be argued that longterm inflammatory exposure appears to cause a dysfunction of Treg cell, resulting in a negative feedback to augment further Treg cell influx) [10, 13-15]; and increases in various inflammatory cytokines such as TNF- $\alpha$, IL-8, IL-1 $\beta$, and IL-32 [16-20]. TNF- $\alpha$ and IL-1 $\beta$ are major inducers of the inflammatory immune response. As inflammatory cytokines, TNF- $\alpha$ and IL- $1 \beta$ can activate nuclear factor- $\mathrm{\kappa B}$ and the mitogen-activated protein kinase signaling pathway in airway epithelial cells, macrophages, and lung tissue cells. Adherence and infiltration of lymphocytes, monocytes, and neutrophils result in lung injury under conditions of inflammation [21, 22] and induce serial inflammatory cytokine expression. IL-32 is mainly expressed in alveolar macrophages and alveolar walls. COPD markedly upregulates IL-32 expression. IL-32 induces the production of TNF- $\alpha$, IL-1 $\beta$, and IL- 8 by nuclear factor- $\kappa \mathrm{B}, \mathrm{p} 38$ mitogen-activated protein kinase, and the caspase- 1 and caspase- 3 
signal transduction pathways. IL-1 $\beta$ may increase to 10 times its baseline level [23-25]. IL-8 is a key cytokine and chemokine that can activate neutrophils. It is mainly synthesized and released by mononuclear macrophages induced by IL-1 and TNF- $\alpha$ [26, 27]. IL-8 induces neutrophils to release elastase, which can injure lung cell walls, and to release a large number of oxygen free radicals that injure lung tissue and directly lead to bronchial smooth muscle spasm [28, 29]. These processes result in airway obstruction and progression of inflammation. In addition, the release of neutrophil elastase induces IL-8 gene expression in airway epithelial cells, leading to a vicious circle of chronic airway inflammation and sustained damage [30]. These disordered immune cells interact with inflammatory factors and form an internal network that can promote sustained progression of COPD.

The main components of milkvetch root are astragalus polysaccharide, more than 40 saponins, more than 30 flavones, 25 amino acids, and various trace elements [31,32]. Milkvetch root has a variety of biological effects: it is a good immunomodulator [33-35], regulates T-lymphocyte function, inhibits nuclear factor- $\mathrm{kB}$ activation, increases the secretory immunoglobulin A content in respiratory mucosa, controls humoral immunity, reduces inflammatory edema of the bronchial mucosa, and controls clinical symptoms in patients with COPD. Milkvetch root suppresses the production of oxygen free radicals, prevents their interaction with membrane lipids to generate lipid peroxides, reduces damage to the biomembrane [36], and suppresses platelet adhesion.

In this study, the serum TNF- $\alpha$, IL-8, IL-1 $\beta$, and IL-32 levels significantly decreased after 14 days of antispasmodic, expectorant, antiasthmatic, and anti-infection treatment in patients with acute exacerbation of COPD in both the experimental and control groups (all $\mathrm{P}<0.01$ ). However, the NK cells, $\mathrm{B}$ cells, and $\mathrm{Th} / \mathrm{Tc}$ ratio significantly increased (all $\mathrm{P}<0.05$ ) and the Treg cells significantly decreased $(\mathrm{P}<0.05)$. These results suggest that the strategy used in this study has definite advantages and is associated with apparent clinical improvement in both FEV1 and FEV1/FVC. These results also demonstrated that the serum TNF- $\alpha$, IL-8, IL-1 $\beta$, and IL-32 levels were significantly lower but that the $\mathrm{Th} / \mathrm{Tc}$ ratio and NK cells were significantly higher in the experimental group (administration of milkvetch root) than in the control group 14 days after treatment (all $\mathrm{P}<0.01$ ). Moreover, Treg cells were significantly lower in the experimental group than in the control group at 14 days $(\mathrm{P}<0.01)$. The above-described results indicated that milkvetch root affected the humoral immunity of patients with acute exacerbation of COPD through its various active ingredients Milkvetch evidently contributed to proliferation and activation of Th cells and NK cells and to the return of Treg cells, weakened the cascade of inflammatory cells and inflammatory cytokines, enhanced protection against infection, and achieved better therapeutic outcomes. The high FEV1 and FEV1/FVC in the experimental group also illustrated this point. Milkvetch root used in this study has various active ingredients, and that ingredients improved the immune function of patients with acute exacerbation of COPD in this study are unknown. This will be an essential component of future studies of the ingredients of milkvetch root.

In conclusion, the application of milkvetch root to antispasmodic, expectorant, antiasthmatic, and anti-infection treatment helps to balance humoral and cellular immunity and improves pulmonary function in patients with acute exacerbation of COPD.

\section{Acknowledgments}

Supported Sources of funding: The Natural Science Foundation of China (81200161), Wuxi Hospital Management Center Project (YGZXM14012), and the Science and Technology Project of the Jiangsu Provincial Chinese Medicine Administration Bureau in China (LB13007). 


\section{References}

[1] R. Laniado-Laborin, Smoking and chronic obstructive pulmonary disease (COPD), Parallel epidemics of the 21 century, International Journal of Environmental Research and Public Health 1 (2009), 209-224.

[2] M.S. Issac, W. Ashur and H. Mousa, Genetic Polymorphisms of Surfactant Protein D rs2243639, Interleukin (IL)-1beta rs16944 and IL-1RN rs2234663 in chronic obstructive pulmonary disease, healthy smokers, and non-smokers, Molecular Diagnosis \& Therapy 3 (2014), 343-354.

[3] H.J. Metcalfe, S. Lea, D. Hughes, R. Khalaf, K. Abbott-Banner and D. Singh, Effects of cigarette smoke on Toll-like receptor (TLR) activation of chronic obstructive pulmonary disease (COPD) macrophages, Clinical and Experimental Immunology 3 (2014), 461-472.

[4] P. Dadvand, M.J. Nieuwenhuijsen, A. Agusti, J. de Batlle, M. Benet, R. Beelen, M. Cirach, D. Martinez, G. Hoek, X. Basagana, A. Ferrer, J. Ferrer, R. Rodriguez-Roisin, J. Sauleda, S. Guerra, J.M. Anto and J. Garcia-Aymerich, Air pollution and biomarkers of systemic inflammation and tissue repair in COPD patients, European Respiratory Journal 44 (2014), 603-613.

[5] L.L. Shen, Y.N. Liu, H.J. Shen, C. Wen, Y.L. Jia, X.W. Dong, F. Jin, X.P. Chen, Y. Sun and Q.M. Xie, Inhalation of glycopyrronium inhibits cigarette smoke-induced acute lung inflammation in a murine model of COPD, International Immunopharmacology 2 (2014), 358-364.

[6] J.L. Huang and Y. Zhang, Research progress of astragalus polysaccharides on anti-inflammatory and immunomodulatory functions, Zhong Xi Yi Jie He Xin Nao Xue Guan Bing Za Zhi 11 (2013), 1374-1376.

[7] Z.Q. Zhao, L.X. Jia, Q.B. Zhang, H.R. Bian, Z.S. Tian, Y.J. Li, H.X. Zhou, C.S. Zhou and L. Li, Effects of flavone on immune function in vivo, Lin Chuang Hui Cui 1 (2014), 49-51.

[8] F.D. Zhao, J.C. Dong and J.Y. Xie, Effects of Chinese herbs for replenishing shen and strengthening qi on some indexes of neuro-endocrino-immune network in asthmatic rats, Zhong Guo Zhong Xi Yi Jie He Za Zhi 8 (2007), 715-719.

[9] Chinese Society of Respiratory Diseases, The guideline of diagnosis and treatment of COPD (2007), Zhong hua Jie He He Hu Xi Za Zhi 1 (2007), 8-17.

[10] S.H. Lee, S. Goswami, A. Grudo, L.Z. Song, V. Bandi, S. Goodnight-White, L. Green, J. Hacken-Bitar, J. Huh, F. Bakaeen, H.O. Coxson, S. Cogswell, C. Storness-Bliss, D.B. Corry and F. Kheradmand, Antielastin autoimmunity in tobacco smoking-induced emphysema, Nature Medicine 5 (2007), 567-569.

[11] Xiong G, Xu L, Wei L and Li X. Atomization inhalation of terbutaline and budesonide efficiently improved immunity and lung function of AECOPD patients, Cellular \& Molecular Immunology 4 (2008), 287-291.

[12] A. Prieto, E. Reyes, E.D. Bernstein, Martinez, Monserrat J, Izquierdo JL, Callol L, de LUCAS P, Alvarez-Sala R, Alvarez-Sala JL, Villarrubia VG and Alvarez-Mon M. Defective natural killer and phagocytic activities in chronic obstructive pulmonary disease are restored by glycophosphopeptical (inmunoferon), American Journal of Respiratory and Critical Care Medicine 7 (2001), 1578-1583.

[13] E. Roos-Engstrand, B. Ekstrand-Hammarstrom, J. Pourazar, A.F. Behndig, A. Bucht and A. Blomberg, Influence of smoking cessation on airway T lymphocyte subsets in COPD, Journal of Chronic Obstructive Pulmonary Disease 2 (2009), 112-120.

[14] M. Profita, A. Sala, A. Bonanno, L. Riccobono, M. Ferraro, S. La Grutta, G.D. Albano, A.M. Montalbano and M. Gjomarkaj, Chronic obstructive pulmonary disease and neutrophil infiltration: role of cigarette smoke and cyclooxygenase products, American Journal of Physiology-Lung Cellular and Molecular Physiology 2 (2010), L261269.

[15] L.J. Smyth, C. Starkey, J. Vestbo and D. Singh, CD4-regulatory cells in COPD patients, Chest 1 (2007), 156-163.

[16] M.L. Moy, M. Teylan, V.A. Danilack, D.R. Gagnon and E. Garshick, An index of daily step count and systemic inflammation predicts clinical outcomes in chronic obstructive pulmonary disease, Annals of the American Thoracic Society 2 (2014), 149-157.

[17] C.H. Chiang, C.H. Chuang and S.L. Liu, Transforming growth factor-beta1 and tumor necrosis factor-alpha are associated with clinical severity and airflow limitation of COPD in an additive manner, Lung 1 (2014), 95-102.

[18] E. Feng, R. Wan, S. Yang, Z. Yan, S. Wang, W. He, Y. Zhang, H. Yin, Z. Chen and R. Liu, Expression levels of induced sputum IL-8 and IL-10 and drug intervention effects in patients with acute exacerbated COPD complicated with chronic corpulmonale at high altitude, Experimental and Therapeutic Medicine 3 (2013), 747-752.

[19] B. Beghe, A. Verduri, B. Bottazzi, M. Stendardo, A. Fucili, S. Balduzzi, C. Leuzzi, A. Papi, A. Mantovani, L.M. Fabbri, C. Ceconi and P. Boschetto, Echocardiography, spirometry, and systemic acute-phase inflammatory proteins in smokers with COPD or CHF: An observational study, PLoS One 11 (2013), e80166.

[20] X. Deng, Z. Zhang, W. Gu, Y. Li and M. Liu, Budesonide inhibits interleukin-32 expression in a rat model of chronic obstructive pulmonary disease, Experimental Lung Research 6 (2012), 295-301. 
[21] T. Xue, N. Wei, Z. Xin and Qingyu Xiu, Angiotensin-converting enzyme-2 overexpression attenuates inflammation in rat model of chronic obstructive pulmonary disease, Inhalation Toxicology 1 (2014), 14-22.

[22] C.L. Doig, J. Bashir, A.E. Zielinska, M.S. Cooper, P.M. Stewart and G.G. Lavery, TNFalpha-mediated Hsd11b1 binding of NF-kappaB p65 is associated with suppression of 11beta-HSD1 in muscle, Journal of Endocrinology 3 (2014), 389-396.

[23] N.Y. Ko, S.H. Mun, S.H. Lee, J.W. Kim, D.K. Kim, H.S. Kim, E. Her, S.H. Kim, H.S. Won, H.S. Shin, H.S. Kim, Y.M. Kim and W.S. Choi, Interleukin-32alpha production is regulated by MyD88-dependent and independent pathways in IL-1beta-stimulated human alveolar epithelial cells, Immunobiology 1-2 (2011), 32-40.

[24] F. Calabrese, S. Baraldo, E. Bazzan, F. Lunardi, F. Rea, P. Maestrelli, G. Turato, K. Lokar-Oliani, A. Papi, R. Zuin, P. Sfriso, E. Balestro, C.A. Dinarello and M. Saetta, IL-32, a novel proinflammatory cytokine in chronic obstructive pulmonary disease, American Journal of Respiratory and Critical Care Medicine 9 (2008), 894-901.

[25] C.A. Dinarello and S.H. Kim, IL-32, a novel cytokine with a possible role in disease, Annals of the Rheumatic Diseases 65 (2006), 61-64.

[26] G. Warwick, P.S. Thomas and D.H. Yates, Non-invasive biomarkers in exacerbations of obstructive lung disease, Respirology 5 (2013), 874-884.

[27] S.S. Kristan, Blood specimen biomarkers of inflammation, matrix degradation, angiogenesis, and cardiac involvement: a future useful tool in assessing clinical outcomes of COPD patients in clinical practice, Archivum Immunologiae Et Therapiae Experimentalis 6 (2013), 469-481.

[28] N. Mukaida, Pathophysiological roles of interleukin-8/CXCL8 in pulmonary diseases, American Journal of PhysiologyLung Cellular and Molecular Physiology 4 (2003), L566-577.

[29] H.G. Moon, Y. Zheng, C.H. An, Y.K. Kim and Y. Jin, CCN1 secretion induced by cigarette smoking extracts augments IL-8 release from bronchial epithelial cells, PLoS One7(2013), e68199.

[30] M.J. Ungurs, N.J. Sinden and R.A. Stockley, Progranulin is a substrate for neutrophil-elastase and proteinase-3 in the airway and its concentration correlates with mediators of airway inflammation in COPD, American Journal of Physiology-Lung Cellular and Molecular Physiology 1 (2014), L80-87.

[31] J. Li, F. Li, Y. Xu, W. Yang, L. Qu, Q. Xiang, C. Liu and D. Li, Chemical composition and synergistic antioxidant activities of essential oils from atractylodes macrocephala and astragalus membranaceus, Natural Product Communications 9 (2013), 1321-1324.

[32] X.Q. Ma, Q. Shi, J.A. Duan, T.T. Dong and K.W. Tsim, Chemical analysis of Radix Astragali (Huangqi) in China: A comparison with its adulterants and seasonal variations, Journal of Agricultural and Food Chemistry 17 (2002), 48614866.

[33] M. Jin, K. Zhao, Q. Huang and P. Shang, Structural features and biological activities of the polysaccharides from Astragalusmembranaceus, International Journal of Biological Macromolecules 64 (2014), 257-266.

[34] W. Li, Y.N. Sun, X.T. Yan, S.Y. Yang, S.B. Song, Y.M. Lee and Y.H. Kim, NF-kappaB inhibitory activity of sucrose fatty acid esters and related constituents from astragalusmembranaceus, Journal of Agricultural and Food Chemistry 29 (2013), 7081-7088.

[35] X. Chen, B. May, Y.M. Di, A.L. Zhang, C. Lu, C.C. Xue and L. Lin, Oral Chinese herbal medicine combined with pharmacotherapy for stable COPD: A systematic review of effect on BODE index and six minute walk test, PLoS One 3 (2014), e91830.

[36] T. Wang, Y. Sun, L. Jin, Y. Xu, L. Wang, T. Ren and K. Wang, Enhancement of non-specific immune response in sea cucumber (apostichopusjaponicus) by astragalusmembranaceus and its polysaccharides, Fish \& Shellfish Immunology 6 (2009), 757-762. 